Supplement of Atmos. Chem. Phys., 20, 9101-9114, 2020

https://doi.org/10.5194/acp-20-9101-2020-supplement

(C) Author(s) 2020. This work is distributed under

the Creative Commons Attribution 4.0 License.

(c) (i)
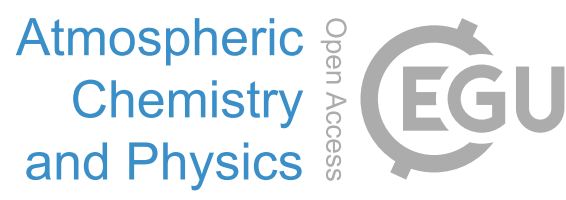

Supplement of

\title{
Contrasting sources and processes of particulate species in haze days with low and high relative humidity in wintertime Beijing
}

Ru-Jin Huang et al.

Correspondence to: Ru-Jin Huang (rujin.huang@ieecas.cn)

The copyright of individual parts of the supplement might differ from the CC BY 4.0 License. 

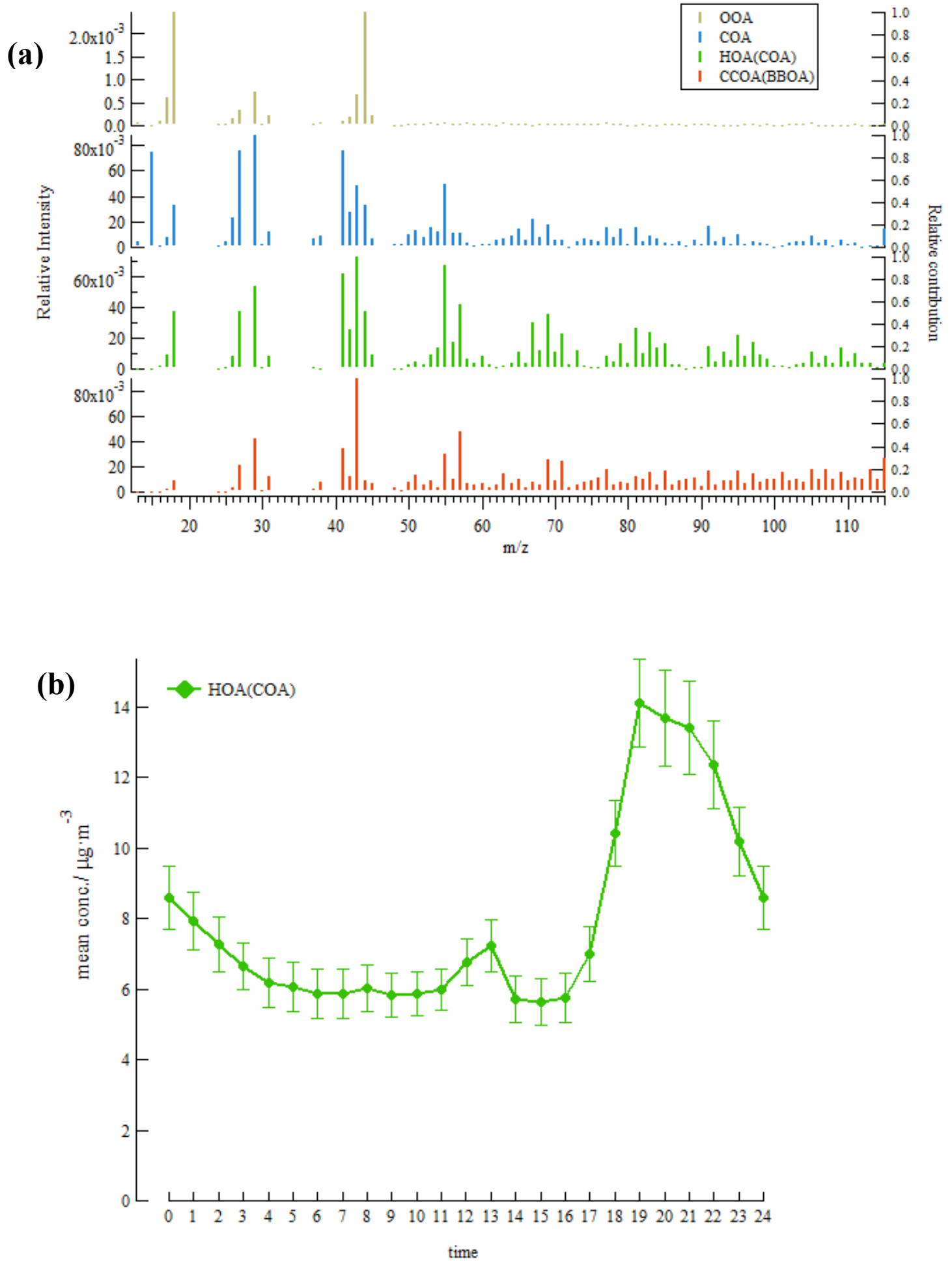

Figure S1. The mass spectra (a) and HOA (COA) diurnal variation (b) for 4-factor solution. 

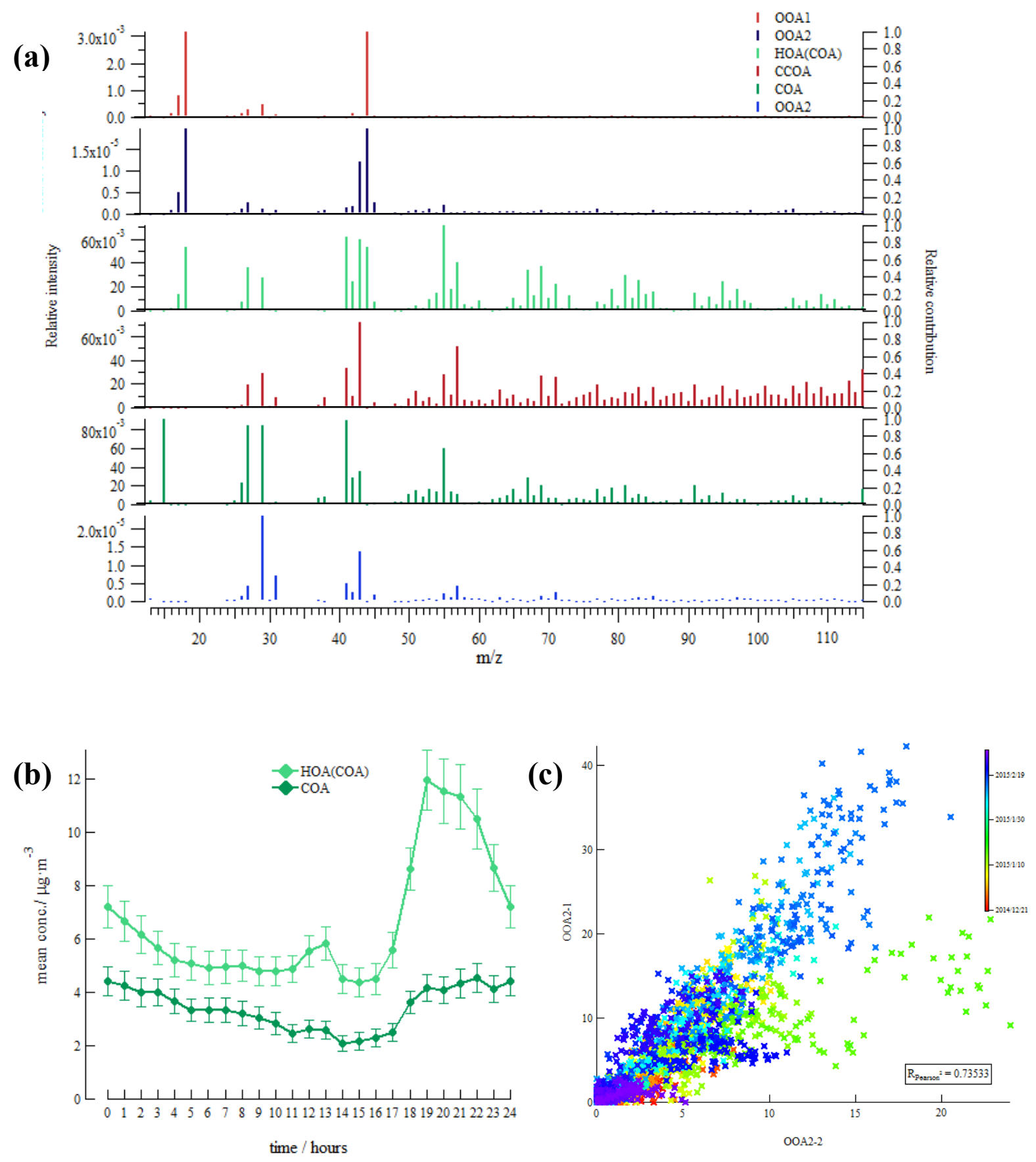

Figure S2. The mass spectra (a), HOA and COA diurnal variations (b), and scatter plot of two 00A2 factors for 6-factor solution. 


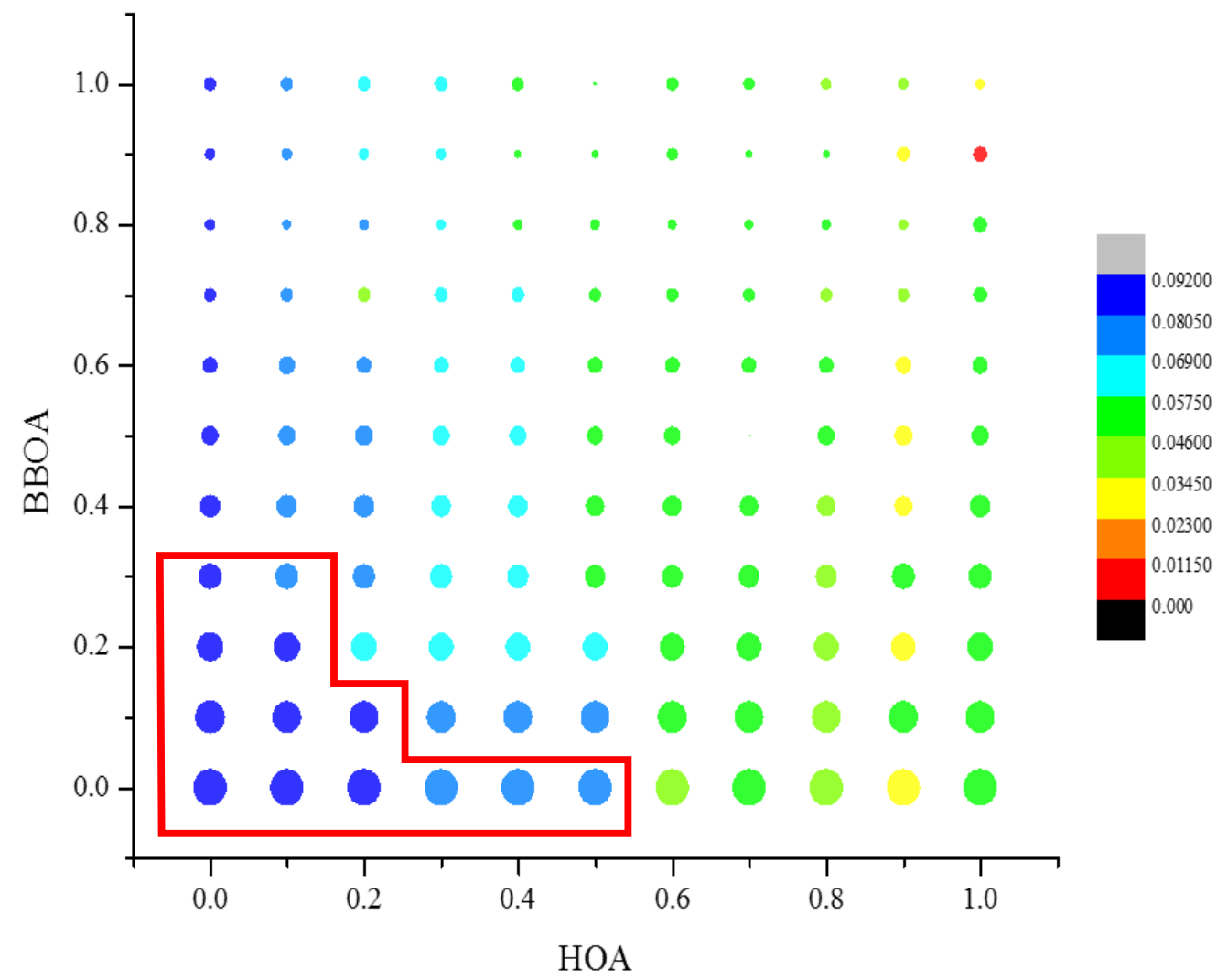

Figure S3. $f_{60}$ of HOA (a, color coded) and $f_{57}$ of BBOA (b, dot size). 


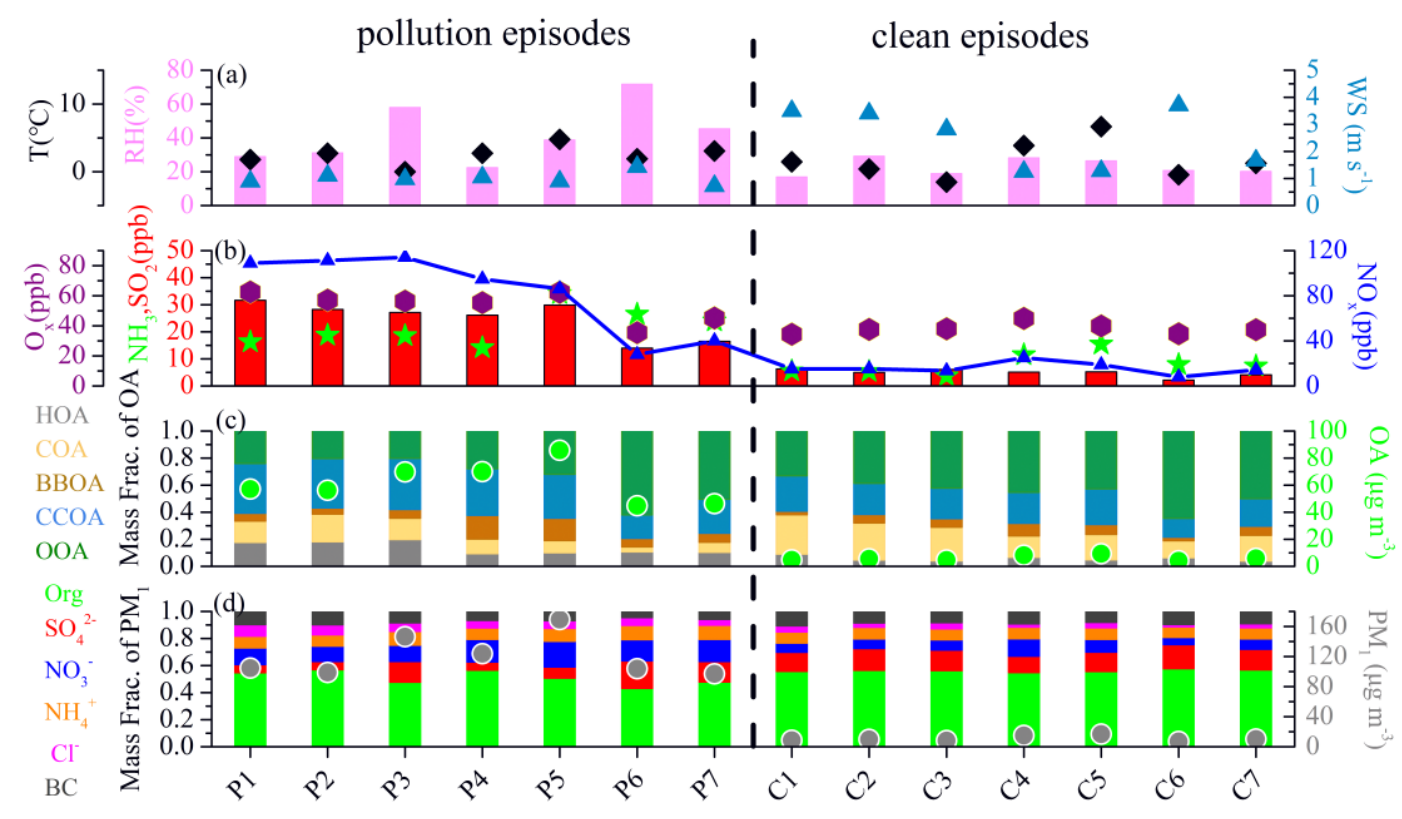

Figure S4. The meteorological parameters (wind speed (WS), temperature (T), and relative humidity $(\mathrm{RH}))$, gas pollutants $\left(\mathrm{O}_{\mathrm{x}}, \mathrm{SO}_{2}, \mathrm{NH}_{3}\right.$, and $\left.\mathrm{NO}_{\mathrm{x}}\right)$, the fraction contributions and mass concentrations of $\mathrm{OA}$ factors and $\mathrm{PM}_{1}$ components during the pollution (P1-P7) and clean (C1-C7) episodes. 